\title{
"NUTRINDO RAIVA, CAUSANDO DOR", OU COMO O ROCK NEOFASCISTA TEM CONSTRUÍDO ÓDIO PELA AMÉRICA DO SUL
}

\author{
Pedro Carvalho Oliveiral
}

\begin{abstract}
RESUMO: O presente trabalho objetiva mostrar como o rock neofascista tem motorizado o crescimento do espaço político de movimentos neofascistas nos países sulamericanos desde os anos 1980, por meio da construção do ódio aos seus antagonistas em consonância intensa com crenças, preconceitos e discursos de ódio já presentes em suas sociedades. Esta dinâmica permite que discursos extremistas se aproximem de outros existentes no senso comum, enraizados em países que passaram por um processo de colonização semelhante, organizado por nações europeias. Por meio de uma análise do conteúdo presente nos discursos de seis bandas do gênero surgidas em três países diferentes (Argentina, Brasil e Chile), perceberemos como o comportamento neofascista estabelece permanências e descontinuidades com os fascismos históricos a depender do que encontram nos terrenos onde atuam.
\end{abstract}

PALAVRAS-CHAVE: Rock neofascista; Neofascismo; Discursos de ódio.

\section{"NURTING ANGER, CAUSING PAIN", OR HOW THE NEO-FASCIST ROCK HAS BUILT HATE ACROSS SOUTH AMERICA}

\begin{abstract}
The present paper aims to show how neo-fascist rock has been driving the growth of the political space of neo-fascist movements in the South American countries since the 1980s, through the construction of hatred toward its antagonists in an intense
\end{abstract}

\footnotetext{
${ }^{1}$ Doutorando em História na Universidade Estadual de Maringá. Bolsista CAPES/Fundação Araucária. Email: pedro.labtempo@gmail.com
} 
consonance with beliefs, prejudices and hate speeches present in their societies. This dynamic allows extremist speeches to approach those existing in common sense, rooted in countries that have undergone a similar process of colonization organized by European nations. Through an analysis of the content present in the discourses of six bands of the genre that have emerged in three different countries (Argentina, Brazil and Chile), we will see how neo-fascist behavior establishes permanence and ruptures with historical fascism depending on what they find in the lands where they operate.

KEYWORDS: Neo-fascist rock; Neo-fascism; Hate speech.

\section{INTRODUÇÃO}

O ódio aos indivíduos percebidos como elementos externos a um ideal de nação pré-concebido, aqueles que não compartilham dos denominadores comuns de tal ou qual sociedade - língua, cultura, passado histórico, herança simbólica, entre outras coisas -, é desde os anos 1920 a pedra fundamental do comportamento fascista. Este ideário não foi destruído com a queda dos regimes de Benito Mussolini na Itália e de Adolf Hitler na Alemanha ao findar da Segunda Guerra Mundial. Transformouse e adaptou-se, ampliou seu espaço de atuação e até hoje assombra a maioria dos países localizados no chamado "mundo Ocidental".

Evidentemente, não podemos dizer que as ideias e as práticas fascistas do presente manipulam pessoas, como Mefistófeles fez com Fausto. Os fascismos são, antes de mais nada, movidos pela manifestação visceral do ódio presente nas sociedades diante de um inimigo determinado a partir de suas características morais, políticas, por vezes raciais e étnicas, e de como elas se distanciam de um todo, ou seja, a nação. Esta não precisa necessariamente ser um país, mas um macro ou mesmo microcosmo de pessoas que se declaram iguais, aptas a execrar os diferentes em nome de uma homogeneização pretensamente necessária ao bem estar, ao enfrentamento de uma crise, constituindo-se em bastião de um coletivo que se diz naturalmente pertencente à nação, contrapondo-se aos "invasores", aos "outros". Por vezes, a noção tradicional de nação é sacrificada para readequar o ódio fascista ao presente, ocorrendo o que alguns autores chamam de nacionalismo territorial ou histórico, havendo recusa ao conceito 
jacobino de nação e definindo-a como uma comunidade orgânica fechada em fatores de pertencimento menos abrangentes (BARBOSA, 2015).

Foi com este espírito que os neofascismos, ou seja, a conjugação das novas formas de ação dos fascismos clássicos no presente, desembarcaram na América do Sul e ampliaram a forma de agir dos militantes neofascistas europeus. Igualmente, buscaram, assim como às suas bases políticas, readequar e reformular conceitos de nacionalismos. Estas formas de agir dos fascismos encontraram na região emblemáticas heranças da presença fascista no passado, como a Aliança Integralista Brasileira, o pioneirismo de Miguel Serrano no Chile e mesmo a Tercera Fuerza na Colômbia ou o Partido Nuevo Triunfo na Argentina. Ao mesmo tempo, adaptaram ao terreno sul-americano narrativas ideológicas que pareciam inadaptáveis, gerando, com isso, uma autenticidade bastante particular. Os neofascismos sul-americanos são tão próximos dos ideais fascistas de outrora quanto são diversos em suas peculiaridades, embrionando um caso único, distinto. Veremos isso em cada exemplo utilizado neste trabalho, analisando especialmente casos no Brasil, na Argentina e no Chile.

Vestígios dos processos que levaram ao crescimento dos neofascismos estão registrados no rock neofascista, gênero musical particular aos movimentos que orbitam o universo deste comportamento político. Trata-se de um tipo de música funcional à propaganda política, sobretudo por ser um terreno de evocação do ódio tradicional a este tipo de extremismo. As músicas não apenas relatam o ódio dos neofascistas aos seus díspares, a um "outro conveniente" (GAY, 1995), mas convidam o ouvinte a senti-lo, a unir-se ao ideal neofascista e lutar por uma sociedade onde ele se estabeleça, triunfando o chauvinismo. Com isso, os neofascistas que produzem este tipo de música por vezes transpõem inimigos dos fascismos clássicos (como os comunistas, os liberais ou os judeus) e criam novos tendo em vista suas próprias sociedades. No Brasil, o ódio pode recair sobre os nordestinos, por exemplo, inimigo particular de parte dos neofascistas do nosso país.

As particularidades dos neofascismos são fundamentais para conhecermos suas diversas facetas. Outros campos do conhecimento, como as ciências sociais, vem os investigando de forma substancial nas 
últimas décadas, o que pode ser constatado em trabalhos de fôlego como os de Márcia Regina da Costa (2000), Jefferson Rodrigues Barbosa (2016), Alexandre de Almeida (2011), entre muitos outros. Jornalistas do Brasil e do mundo também tem se debruçado sobre este objetivo, a exemplo de Ricardo Ampudia (2006), Antonio Salas (2006) e Antonio Moyano (2004). Entre os historiadores, podemos destacar os já consagrados olhares de Francisco C. Teixeira da Silva (2004) sobre a questão, além dos esforços de laboratórios como o Grupo de Estudos do Tempo Presente, da Universidade Federal de Sergipe, que há anos vem mapeando e investigando movimentos neofascistas, resultando em robustas inspeções sob a coordenação do pesquisador Dilton Maynard (2017).

O esforço de diversas áreas do conhecimento busca, para além da localização de peculiaridades deste objeto - ampliando as possibilidades de acuradas análises, para compreender mais a fundo o seu desenvolvimento -, tem sido crescente para acompanhar os movimentos neofascistas que ganham fôlego no presente. Na Polônia, na Itália, na Espanha, no Reino Unido, nos Estados Unidos, enfim, em diversos países mundo Ocidental, estes movimentos vem servindo como flanco radical para a dispersão de opositores, dos grupos sociais considerados "inimigos", de todo e qualquer discurso que se distancie de um nacionalismo extremado e violento incorporado por alguns partidos políticos e movimentos sociais. Nestes países, ao passo em que personagens e atitudes extremistas ampliam sua popularidade como pretensas soluções fáceis a problemas complexos, seus adeptos mais radicais sentem-se à vontade para agir violentamente tendo a defesa da nação como desculpa, mas motorizados pelo ódio ao "outro". Localizar estas particularidades dos neofascismos sul-americanos é conhecer suas nuances e como constroem o ódio nas sociedades em que vivem: praticando uma energização utilitária contra possíveis responsáveis por qualquer problema em seus países, dando forma distinta ao seu comportamento político e se aproximando da população na medida em que ela pode compartilhar de um mesmo ressentimento, mesmo não estando imersa no fascismo. Faremos isso examinando letras das bandas Ultra Sur e Nüremberg (Argentina), Comando Blindado e Defesa Armada (Brasil) e Odal Sieg e Orgullo Sur (Chile). Assim, poderemos apresentar uma amostra de 
como os neofascismos sul-americanos estruturam seus discursos de ódio visando uma penetração maior no espectro social.

Entendemos que neofascismos são correntes ideológicas tributárias dos fascismos clássicos, ou seja, aqueles que surgiram nos anos 192030, adaptando seu comportamento ao tempo presente e incorporando elementos dos contextos em que agem. Utilizando o plural, nos referimos como neofascismo também o neonazismo, visto que a narrativa ideológica hitlerista era uma modalidade de fascismo, embora possua alguns elementos próprios, diferentes do movimento italiano. O racismo, por exemplo, embasou o nazismo desde seu surgimento, característica que contagiou o fascismo italiano apenas mais tarde. A superioridade racial somente se tornou pauta fascista com a ascensão nazista. Da mesma forma, o integralismo brasileiro possuía distinções, mesmo que, a despeito disso, não tenha deixado de ser uma ideologia fascista, assim como o nazismo. É com esta perspectiva que analisaremos os casos no decorrer do artigo.

\section{O ROCK NEOFASCISTA COMO DIFUSOR DE ÓDIO}

O rock neofascista surgiu na Inglaterra no início dos anos 1980, em meio ao boom do movimento punk e do retorno da subcultura skinhead. ${ }^{2}$ A música de protesto e de inconformismo social dos punks fez com que os skinheads, há muito marginalizados na sociedade inglesa, retomassem suas origens e incorporassem a perspectiva contracultural do movimento punk, ambos expressando seu descontentamento juvenil por meio do rock. Porém, a Inglaterra e toda a Europa viviam também uma profunda crise econômica e política, consequência do arrefecimento dos ganhos frenéticos da industrialização dos anos 1950-60, agravada pelo desemprego estrutural que levava milhares de pessoas à pobreza e o Estado à recessão.

Neste cenário, movimentos e partidos neofascistas como o National Front e o British National Party despontaram como solução para

\footnotetext{
${ }^{2}$ Devemos esclarecer que até o final dos anos 1970, a subcultura skinhead não era contaminada pelas ideias neofascistas com as quais muitos de seus integrantes passariam a se identificar. Desde os anos 1960 foi uma subcultura que incorporava elementos da cultura jamaicana e operária, não a segregação racial e nacionalista com a qual se envolveria mais tarde.
} 
a crise, discursando contra a esquerda - que supostamente tolerava a imigração, culpada pela falta de empregos para os europeus - e contra a direita liberal - acusada de ter levado a Inglaterra à crise. Liberalismo e socialismo eram representados por estas organizações como modelos políticos ultrapassados, devendo ser substituídos por uma "terceira via" nacionalista, empenhada na crítica aberta a migrantes, negros, judeus e todos considerados inimigos do Reino Unido por estarem em desacordo com o que pensavam ser os verdadeiros britânicos (COPSEY, 2004). Com isso, estimulavam um resgate às raízes culturais britânicas, a uma história e um passado idílico aparentemente compartilhado pelos reais descendentes daquela nação, à qual deviam se voltar para superar a crise. Para os neofascistas, a Inglaterra havia sucumbido aos "outros", aos "não pertencentes".

No bojo desses acontecimentos, alguns skinheads foram cooptados pelos partidos neofascistas para atuarem como linha de frente da juventude, angariando possíveis eleitores e pessoas engajadas em espalhar suas ideias mesmo que pela força. Ian Stuart Donaldson foi um deles. Líder da banda londrina Skrewdriver, mudou radicalmente sua forma de compor ao passo em que mergulhou de cabeça no National Front. Suas posturas neonazistas ficaram cada vez mais claras e os discursos de ódio, em sintonia com os de seu movimento, mais acentuados. Nascia assim o rock neofascista.

Entre o início dos anos 1980 até os dias de hoje (anos 2010), o gênero se espalhou pelo Ocidente com velocidade. Gravadoras como a alemã Rock-O-Rama e a francesa Rébelles Europeens ajudaram em muito neste processo. A organização Blood \& Honour, criada por Donaldson em 1987, foi fundamental para catapultar o rock neofascista pelo mundo: divulgava, produzia, organizava e distribuía material musical muito antes de a Internet se tornar um meio de comunicação comum. Quando isto ocorreu, o gênero se disseminou com maior vigor.

Organizações como a estadunidense Hammerskin e lojas virtuais como a NS88 Division organizam eventos e vendem produtos de rock neofascista desde os anos 2000 de forma simples, estando a poucos cliques de qualquer pessoa. Não estão em páginas obscuras da rede, pois podem ser facilmente encontradas em sites de busca. Redes de streaming 
como Spotify e Deezer abrigavam, sem saber, vastas discografias de bandas neofascistas há pouco tempo. Blogs e fóruns voltados à divulgação deste tipo de música são numerosos. Isto certamente possibilitou a amplitude do perímetro no qual gênero é ouvido e produzido na América do Sul. Com ele, novas formas de construir o ódio.

Alguns autores, a exemplo de Antonio Salas (2006), referem-se a este gênero como hate music. Outros, como nós, já utilizamos o termo hate rock para reduzir sua escala de alcance e circunscrevê-lo em sua especificidade sonora. Não se trata de um gênero que abarca diversos tipos de música, mas sim um tipo específico: o rock. Ao nomeá-lo como rock neofascista estamos, por um lado, sinalizando para o fato de que estas bandas exaltam ideias neofascistas e, por outro, que a forma como constroem o ódio é cercada por estas ideias. Portanto, trata-se de um gênero que não simplesmente difunde o ódio, mas que o faz tendo em vista "inimigos" estabelecidos no passado por suas ideologias e outros novos, possibilitados por um tipo de comportamento político em histórico processo de transformação.

\section{QUEM OS NEOFASCISTAS SUL-AMERICANOS ODEIAM E PORQUÊ}

O rock neofascista chega à América do Sul no início dos anos 1980. No Brasil, o desembarque da subcultura skinhead já contagiada por ideias neofascistas ou de nacionalismo extremista permitiu com que este comportamento já estivesse presente em suas primeiras manifestações artísticas. Desde então, há fortes marcas de discursos de ódio contra migrantes, homossexuais e, mais tarde, negros entre os skinheads que se estabeleceram primeiro em São Paulo (COSTA, 2000). Na Argentina, a banda Comando Suicida, fundada em 1983, deixou de ser uma banda próxima à $O i !$ music para se converter em símbolo da penetração neofascista no país. Nos outros países da região, o gênero musical chegou acompanhado da subcultura skinhead de forma mais ou menos uniforme, variando pouco quanto ao tempo (OLIVEIRA, 2018). 
Foi nos anos 1990, contudo, que vimos um crescimento assombroso do rock neofascista sul-americano. No Brasil, bandas como Locomotiva e Grupo Separatista Branco se tornaram proeminentes. A Odal Sieg deu seus primeiros passos no Chile, enquanto a Nüremberg e Ultra Sur engatinhavam na Argentina para, mais tarde, tornarem-se grandes nomes em suas respectivas cenas musicais. Sincronicamente, nas últimas décadas do século XX, o Chile se convertia na capital sulamericana do neonazismo, sobretudo pela atuação de indivíduos como Miguel Serrano, Alex López, Ernesto Lutz e organizações como a Patria Nueva Sociedad, Frente Orden Nacional e Acción Nacional-Socialista de Chile (MOURA; MAYNARD, 2012). Já na Argentina, observávamos a retomada do Partido Nuevo Triunfo de Alejandro Carlos Biondini e a ascensão da página Ciudad Libre Opinión, plataforma de difusão política de suas ideias abertamente neofascistas.

$\mathrm{Na}$ Colômbia, a organização Tercera Fuerz̧a buscava rememorar um movimento nacional fortemente atrelado ao nazismo nos anos 1950, utilizando a Internet como meio privilegiado de atuação. Organizou festivais em homenagem a Rudolf $\mathrm{Hess}^{3}$ com a participação de uma banda íntima a este movimento, a Orgullo Nacional (OLIVEIRA, 2018). Já no México, um mapeamento da confluência de forças políticas deste tipo ainda necessita ser realizado com maior zelo, visto que ainda conhecemos muito pouco sobre eles. Porém, o caso brasileiro, mais próximo a nós, é sem dúvida um dos mais ricos em episódios que atestam surgimento de bandas neofascistas em todo o território nacional.

Uma das mais importantes vem do Rio Grande do Sul e se chamava Comando Blindado. Formada ainda no final dos anos 1990, chegou a lançar um álbum pelo selo Zyklon-B Records, dos Estados Unidos, em 2006. Intitulado "Marchando rumo à vitória", o disco tem sua capa ilustrada por soldados e bandeiras nazistas. Nele, encontramos a música "Nutrindo raiva, causando dor", na qual ouvimos: "O inimigo esta perto, esta

\footnotetext{
${ }^{3}$ Rudolf Walter Richard Hess (1894-1987) foi delegado do führer, nomeado ao cargo pelo próprio Adolf Hitler em 1933, quando este chegou ao poder na Alemanha. Trata-se de um dos políticos nazistas de maior respeito dentro do partido, tendo sido designado à Escócia em 1941 para negociar termos de paz com o Reino Unido, incumbência que desvela a confiança de Hitler em seu potencial.
} 
controlando você/Invade sua mente através do jornal e da TV/São os malditos judeus que tem o controle das massas/Que dominam a mídia e promovem tanta desgraça". 4

Os judeus são os inimigos número um do nazismo. Desde os anos 1930 os nazistas, já sob a égide de Adolf Hitler, enxergavam uma suposta conspiração judaica "em todos os níveis da sociedade: na economia, na imprensa, nas Forças Armadas, nos partidos políticos, etc.” (GINZBURG, 2006, p. 201). Para eles, o mal que o judeu representava ultrapassava suas práticas religiosas: estava em seu sangue, na sua raça, compreendida por Hitler como culpada por destruir a Alemanha no fluxo de uma obscura conspiração sionista (TEIXEIRA DA SILVA, 2014). Assim, dos anos 1930 aos anos 2000 os judeus foram classificados pelos adeptos desta narrativa ideológica como inimigo, aqueles que não podem ser tratados como humanos para que, desta forma, seja autorizada qualquer tipo de violência capaz de atentar contra suas vidas. Descritos como "malditos", os judeus foram tratados como algo que deve ser afastado, algo maléfico.

Em "Cada vez te odeio mais", a banda se manifesta sobre outros alvos de seu ódio: "Cresce a violência e meu ódio aumenta mais/E o podre comunismo se alastra como doença ruim/Nordestinos vem pro Sul, que infelicidade/Estamos perdendo nossa identidade". ${ }^{5}$ O ódio ao comunismo, assim como às democracias liberais, é marca comum às ideologias fascistas. A fundação do Partido Fascista Italiano foi comemorada em 1919 com a destruição da sede do Partido Comunista. A perseguição a comunistas e democratas foi uma constante durante a ascensão do movimento fascista italiano; eles também não foram poupados pelos nazistas, na Alemanha (PAXTON, 2007). No Brasil, um país que no ano 2006 era governado por um partido identificado como de esquerda (o Partido dos Trabalhadores), o ódio ao comunismo foi recuperado pela banda. Porém, há mais: no mesma alçada estariam os nordestinos, culpados por uma dita "perda de identidade" entre os sulistas.

\footnotetext{
${ }^{4}$ Ver: COMANDO Blindado. "Nutrindo raiva, causando dor". In: Marchando rumo à vitória. EUA: Zyklon-B Records, 2006, faixa 07. 01 CD.

${ }^{5}$ COMANDO Blindado. "Nutrindo raiva, causando dor". In: Marchando rumo à vitória. EUA: Zyklon-B Records, 2006, faixa 01. 01 CD.
} 
O ódio aos nordestinos é marca particular dos neofascistas brasileiros do Sul e Sudeste. Para estes, a região Nordeste é atrasada e seu povo resulta da fusão entre um ambiente naturalmente desfavorável e raças consideradas inferiores, como negros e indígenas. A miscigenação seria a causa da inferioridade dos nordestinos, distantes do ideal de raça pura dos neonazistas. Ao mesmo tempo, os nordestinos são percebidos como dotados de outro passado histórico: o da colonização desenfreada, cujo modelo social ainda resiste, em contraposição à modernização industrialista do Sul-Sudeste, de uma suposta formação étnica hereditária à cultura europeia, por isso caucasiana, e de uma pretensa natureza desenvolvida (OLIVEIRA, 2018). Trata-se, é claro, de uma visão vazia de representações que possam ir além de preconceitos, de um conhecimento raso sobre a história do Brasil, no qual não há a compreensão sobre o que foi a colonização, a industrialização, os nordestinos ou os grupos que povoaram o Sul-Sudeste.

Neste sentido, aos nordestinos é destinado um ódio reservado a todos aqueles que supostamente não correspondem ao ideal de sociedade almejado pelos neofascistas de uma determinada região. Esta particularidade corresponde à formação histórica do Brasil onde diferentes territórios se desenvolveram industrialmente de formas distintas, inclusive tendo o Nordeste perdido sua primazia em relação ao Centro-Sul em meados da década de 1920, e mais ainda com o industrialismo varguista dos anos 1930. A modernização do Sul-Sudeste se chocava com o modelo social tido como "arcaico" do Norte, onde resistia, sobretudo no interior, a sociedade de engenho. Este reducionismo, que à época era deficiente de críticas a problemática relação entre moderno-arcaico, foi amplamente utilizados por teóricos como Oliveira Viana para difundir, à luz de pseudociências eugenistas, a ideia de que o Sul-Sudeste era naturalmente superior ao Norte-Nordeste. Havia nisso uma necessidade de estabelecer vínculo com uma cultura europeia, da qual as pessoas desta região seriam majoritariamente herdeiras.

Esta narrativa ideológica certamente influenciou o pensamento da banda paulista Defesa Armada, como podemos verificar ao ouvirmos "Invasão", música do seu primeiro álbum de estúdio "São Paulo Paulista": 
"São Paulo, terra nossa/Está sendo invadida, está sendo destruída/São Paulo pátria/Está ficando doente, está ficando decadente/São Paulo, nosso orgulho/Está sendo pilhada, roubada e pilhada". ${ }^{6} \mathrm{O}$ discurso da banda é o de que São Paulo, uma terra distinta, está sendo invadida e destruída. Se está sendo invadida, podemos afirmar que quem vinha lhe destruindo era alguém de fora, exterior ao seu território. Na música seguinte, "Inimigo da pátria", há evidências de quem são estes elementos externos: "Tivemos pena daquele povo que sofria/Vocês vieram invadindo o terminal do Tietê/Querendo impor suas maneiras e costumes/Aniquilando a nossa segurança nacional/Fora, estrangeiro, inimigo da pátria". ${ }^{7}$ O terminal do Tietê ficou conhecido como símbolo da imigração nordestina para São Paulo nos anos 1990. A referência a ele, associada ao claro ódio da banda aos estrangeiros, não é desprovida de propósito. Este é mostrar identificação com uma herança histórica diferente daquela compartilhada entre os nordestinos, como se não fizessem parte de uma mesma nação.

Os neofascistas argentinos muitas vezes partem de uma mesma premissa. A banda Ultra Sur, em sua música Fiel Camarada (2009), nos fornece um exemplo claro disso: "Fiel camarada de todas as lutas/Unidos pelo sangue e pelas mesmas ideias/Passamos por dias escuros e muitos mais virão/Odeio quem não é como você, quem não traz em si a herança europeia". ${ }^{8}$ Há um esforço para criar conexão com uma herança europeia a todo custo, como se isso fosse necessário para justificar o alinhamento dos compositores às ideias de pureza racial de Adolf Hitler, ao menos neste caso. E se a banda odeia todos que não são assim, odeia a maior parte da humanidade. Para eles, os argentinos só podem assim ser chamados se estiverem circunscritos por este mesmo passado histórico e étnico: o das invasões europeias e da chegada dos brancos às Américas (OLIVEIRA, 2018).

\footnotetext{
${ }^{6}$ DEFESA Armada. "Invasão”. In: São Paulo Paulista. São Paulo: Independente, 1995, faixa 03. 01 CD.

${ }^{7}$ DEFESA Armada. "Inimigo da pátria". In: São Paulo Paulista. São Paulo: Independente, 1995, faixa 04. 01 CD.

${ }^{8}$ ULTRA Sur. Fiel Camarada. In: Nascido para ser skin. EUA: Label 56, 2009, faixa 08. 01 CD. Tradução nossa.
} 
Puño de acero, música do mesmo álbum, também aponta para um caminhar dos neofascismos argentinos neste mesmo sentido: "Skinheads nacional-socialistas, punhos de ferro contra o regime sionista/Buscando a sagrada liberdade para nossa nação respirar/O poder branco em unidade mundial, até a vitória o caos terminará". ${ }^{9}$ Mais uma vez a narrativa antissemita aparece. Embora, assim como a Alemanha dos anos 1930, a Argentina não possuísse no fim dos anos 2000 uma preponderância visível de judeus na sociedade, é a perspectiva nazista tradicional, embasada na conspiração sionista, que guia o ódio da banda. Isto, pensam seus compositores, estabelece - ou tenta estabelecer - uma conexão com a violenta perseguição aos judeus empreendida na Europa, não apenas na Alemanha, visto que também em outros países os judeus, desde antes do século XX, eram notados como forasteiros, membros de uma sociedade sem pátria e de hábitos distantes daqueles que a moral cristã ajudou a difundir.

A banda Nüremberg, em sua ânsia por reafirmar uma pretensa proximidade com a cultura europeia em contraposição às culturas rejeitadas pelo nazismo, defende mais uma vez a herança histórica como fonte de distinção, de preservação de uns e demonização de outros. Vemos fragmentos deste pensamento na música 14 palabras, do disco Camarada: "Guardião da nossa estirpe, cultura e tradição/As defenda com sua vida, paixão e amor/Herdeiro de uma história, continue sua evolução/ Devemos assegurar a existência de nossa raça/E um futuro para as crianças brancas". ${ }^{10}$ A banda defende a salvaguarda dos brancos, o que pressupõe a luta contra outras raças. Os brancos e sua história devem ser preservados mesmo que para isso, por meio de luta que assegurem seu futuro, como se este estivesse ameaçado, precisem existir sem outras raças. A referência às 14 palavras de David Lane, ideólogo racista cultuado de forma massiva pelos neofascistas, deixa entrelinhado seu pensamento de que uma grande guerra racial ocorrerá e os brancos devem, a qualquer custo, assegurar

\footnotetext{
${ }^{9}$ ULTRA Sur. "Puño de acero". In: Nascido para ser skin. EUA: Label 56, 2009, faixa 04. 01 CD. Tradução nossa.

${ }^{10}$ NÜREMBERG. "14 palabras”. In: Camarada. Alemanha: Gjallarhorn Klangschmiede, 2009, faixa 06. 01 CD. Tradução nossa.
} 
sua existência, discurso assentado na paranoia conspiracionista comum ao nazismo.

Vemos nos exemplos brasileiro e argentino elementos de descontinuidade e continuidade com os fascismos clássicos pela forma como eles odeiam. Nos dois casos há ódio, que é construído tendo como base uma herança ancestral europeia, reivindicada pelos compositores da música para respaldarem seus comportamentos. Se aproximam sobremaneira do nazismo pela manutenção do antissemitismo nacionalista. Porém, no caso brasileiro, há um distanciamento parcial quanto ao modelo clássico: a presença de um novo "inimigo", o nordestino, um "outro" que não fazia parte do acervo nazista de "inimigos nacionais". Contudo, verificamos como uma marca tradicional dos fascismos se mantem: o ódio não precisa se destinar a alvos específicos, pois eles variam a depender de uma série de fatores.

O ódio fascista é contra o "outro", todos aqueles que não fazem parte do "nós" definidos nos círculos particulares que exaltam estas ideologias. Há, evidentemente, o ódio intrínseco a alguns tipos sociais considerados antinacionais, incompatíveis com os denominadores comuns dos que devem ser o corpo homogêneo da nação. Porém, a depender da constituição histórica de uma nação alguns "outros" podem variar. Nos EUA, por exemplo, onde até os anos 1960 vigorou uma segregação institucionalizada em muitos estados e onde o protestantismo possuí espaços onde encontra seguidores fundamentalistas, o ódio aos negros e aos judeus é frequente entre os neofascistas, pois estes não escapam às referências históricas de suas ideologias. No Brasil dos anos 1930, a AIB não rejeitava os negros, ao contrário: estimulava a presença deles em suas frentes, mesmo que ocupando uma posição secundária. Contudo, nenhum negro chegou a assumir cargos de liderança efetiva na AIB, além de os membros brancos de uma organização tão extensa serem frequentemente adeptos da eugenia. $\mathrm{O}$ antissemitismo, por sua vez, era chave da construção identitária dos fascistas brasileiros em decorrência da fundamental base católica da organização (PAXTON, 2007).

O Chile também conhecia um movimento fascista efervescente nos anos 1930. O Movimento Nacional-Socialista do Chile era bastante ativo 
e sua simpatia pelo nazismo não era segredo. É evidente entre as bandas neofascistas do país um vínculo muito forte com esta ideologia, como podemos observar nos discursos musicais da banda Odal Sieg, uma das mais reconhecidas da cena nacional. Gran Mission é uma música que ilustra bem isso: "O chamado do sangue transborda até o pensamento/Nossa herança ancestral clama pelo seu ressurgimento/Abrace nossa causa, cuide de sua origem/Torne-se parte desta grande missão". ${ }^{11}$ Percebemos que de forma a convocar os ouvintes, a banda evoca esta "herança ancestral" que, tendo em vista o vínculo da banda com a ideologia hitlerista, é formada pelos traços hispânicos e pela presença dos primeiros brancos nas Américas.

O mito da herança europeia vai além quando percebemos um detale na música Un buen dia para morrir, da mesma banda: "Em combate, você fez sua voz ser escutada/As vitórias do passado em nossas memórias viverão/ Deixe que as valquírias te conduzam ao lugar dos homens valentes/ Onde o guerreiro sempre viverá"12. $\mathrm{Na}$ mitologia nórdica, as valquírias eram deusas de menor poder que serviam a Odin, sobretudo no processo de encaminhamento dos guerreiros vikings ao Valhalla, paraíso dos guerreiros nórdicos. A mitologia nórdica, adorada pelo ideólogo chileno Miguel Serrano, era também uma das grandes paixões de Adolf Hitler e de Heinrich Himmler, ${ }^{13}$ um de seus braços direitos (SALAS, 2006). É deste universo que vem a obsessão de ambos pelo crescimento do espaço vital, onde a raça ariana viveria harmoniosa e homogeneamente. Para que isso existisse, outras raças precisariam ser destruídas.

Tendo em vista a busca pela homogeneidade racial, é comum que as bandas de rock neofascista apoiem a violência contra grupos e movimentos sociais que apoiam a diversidade étnica. Exemplo disso está na música Botas y violencia, da banda chilena Orgullo Sur. "Vejam só quem aparece, sim, os hippies e punks/Com suas visões de sociedade, por aqui

${ }^{11}$ ODAL Sieg. “Grand mission”. In: Nuevos Guerreros. Paris: Pit Records, 2001, faixa 02. 01 CD. Tradução nossa.

${ }^{12}$ ODAL Sieg. "Un buen día para morrir". In: B\&H Southland Vinland Friendship. Paris: Street Fighting Records, 2004, faixa 0301 CD.. Tradução nossa.

${ }^{13}$ Heinrich Lutipold Himmler (1900-1945) foi comandante da Reichsführer das Schutzstaffel (SS) e um dos principais líderes do partido nazista. Comandou diversas escursões à Escandinávia para buscar artefatos e investigar mitos da mitologia nóridca. 
não irão passar/Péssimo dia para aparecer, pois os skinheads querem diversão/Péssimo dia para caminharem pelo nosso bairro". ${ }^{14}$ A ameaça embutida na música se faz a movimentos culturais que tradicionalmente tem se posicionado junto a um espectro político mais progressista, os hippies e punks, cujas posturas frente à sociedade enfrentam o racismo, a desigualdade e a cultura da virilidade. Esta última é exaltada pelos neofascistas, visto que seus discursos constantemente são direcionados pela imagem do guerreiro, do combatente, corajoso e másculo.

O que fica comprovado com a leitura deste conteúdo discursivo é que os neofascismos sul-americanos possuem uma tendência a buscar laços com uma hereditariedade europeia, algo que, por um lado, os aproxima dos fascismos clássicos e de si mesmos, mas, por outro lado, a depender da formação histórica do campo de onde discursam, este fato possibilita a criação de novos e específicos "inimigos". No caso brasileiro, além da busca pela aproximação com o Velho Mundo e com uma herança cultural branca, há uma particularidade na forma como constroem o ódio ao inimigo: isto pode ser energizado contra grupos sociais de um mesmo território, tornando frágeis as tradicionais concepções de nação tão caras aos fascismos de ontem e de hoje.

\section{CONSIDERAÇÕES FINAIS}

O rock neofascista é um gênero musical por meio do qual o ódio de seus compositores é estruturado e difundido, podendo se mesclar a uma ou outra manifestação de ódio praticada pela sociedade, convidando outras pessoas a praticá-las junto a eles. Transmite uma ideia de sociedade contraposta aos "inimigos" que supostamente circulam por ela, aptos a destruírem-na quando for chegada a hora. Para ideias neofascistas, o ódio é um combustível pois resulta do ressentimento, coluna vertebral deste comportamento. Assim, tratando-se de um ideário constituído no passado, este cerne é recuperado por indivíduos no presente e, com isso, acrescentam ao pensamento fascista novos elementos e novas formas de proceder.

\footnotetext{
${ }^{14}$ ORGULLO Sur. "Botas y violência”. In: Rehersal. Santiago: Independente, 2013, faixa 11. 01 CD. Tradução nossa.
} 
Os fascistas europeus não precisavam se preocupar em estabelecer uma conexão hereditária com povos fora da Europa, como fazem os neofascistas sul-americanos. Os povos de quem se auto-intitulam herdeiros - sem, contudo, levar em consideração que esta hereditariedade nem sempre é pura, desprovida de misturas e embricamentos - eram os próprios europeus, mas de um passado que lhes servia como referência, como berço de sua cultura que, diziam, estava sendo ameaçada por forças externas. Quando os neofascistas sul-americanos buscam esta hereditariedade, negam os elementos constitutivos de sua história, qual seja, aquela permeada pela presença dos povos originários americanos, forçando uma conexão que por vezes poderia ser questionada até mesmo pelos neofascistas europeus, visto que estes frequentemente rejeitam os latino-americanos independentemente de qualquer possível genealogia.

Este processo pressupõe um estímulo mais forte ao ódio, a fim de compensar a ausência das garantias que os neofascistas entendem existir quanto à sua verdadeira descendência europeia. Ressaltam a desumanização dos "inimigos" clássicos dos fascismos e de alguns outros que podem, mais ou menos, serem também rejeitados por parte da sociedade na qual atuam, como o caso dos nordestinos no Brasil. Estes acabam se tornando vítimas do ódio neofascista por já serem alvo do ódio de setores da sociedade imbuídos de preconceito e perspectivas racistas, mesmo que estejam distantes de serem neofascistas.

A construção do ódio empreendida pelos neofascistas e documentadas em suas músicas perpassa ao menos duas dimensões. Primeiro, a histórica, seja por buscar remontar no presente os "monstros" determinados pelos fascismos clássicos ou por suas próprias sociedades no espaço e no tempo e, segundo, pela ânsia em se estabelecerem como neofascistas legítimos como se isto fosse realmente necessário para que práticas violentas resultantes de discursos de ódio sejam praticados.

Não devemos nos questionar se os neofascistas sul-americanos são legítimos ou não, pois atuam em terrenos vastamente mistos, no qual as raças e as culturas se engendram mesmo que sejam negadas por muitos. Não podemos nos restringir a acusá-los de não serem verdadeiros herdeiros dos europeus, pois isto faz pouquíssima diferença. O ódio 
continua sendo difundido e, em muitos casos, convertendo-se em atos de violência em meio à sociedade civil. Quando o ressentimento e o ódio são construídos ao ponto de gerarem em outras pessoas a sensação de não estarem sozinhos na cruzada contra todos aqueles que creem não serem humanos, não existe limitações técnicas que os impeçam.

Precisamos compreender que os neofascismos devem ser levados a sério como comportamentos políticos embasados no ódio e no estímulo à violência; no entendimento de que destruir seus "inimigos" é um ato de coragem; e de que há, a todo momento, uma conexão com o passado que objetiva zelar pelo presente de tais ideologias, sem com isso conseguir escapar ao presente. Desta forma, novos alvos de ódio podem ser criados e construídos em consonância com as especificidades de cada região. A música, de forma inovadora e chamativa, exerce papel relevante na construção social do ódio pelos neofascistas.

O rock neofascista é ainda um gênero musical que apenas arranha a superfície; sua produção, disseminação e consumo tem se restringido a nichos pequenos, a uma cena musical pouco conhecida e frequentada. Contudo, o ódio que movimenta o gênero pode, em muitos casos, aproximar-se do ódio que de forma mais ou menos velada pode estar disseminado em uma sociedade, direcionado aos mais diversos tipos de grupos sociais, minorias, movimentos políticos etc. A radicalização de seus discursos parece ainda afastar a maioria das sociedades, mas é preciso investigarmos com cautela como as linhas entre o ódio político da sociedade não identificada com os neofascismos e estas ideologias podem ser tênues. 


\section{REFERÊNCIAS BIBLIOGRÁFICAS}

ALMEIDA, Alexandre de. "A locomotiva skinhead: a relação entre a música e a memória na construção da identidade de uma organização White Power paulista". I Seminário Internacional de História do Tempo Presente, Florianópolis: UDESC; ANPUH-SC; PPGH, pp. 04-10, 2011.

AMPUDIA, Ricardo. Odiados e orgulhosos: Um mapa da ação organizada dos grupos skinheads no estado do Paraná. Ponta Grossa: Universidade Estadual de Ponta Grossa, 2006.

BARBOSA, Jefferson R. Chauvinismo e extrema-direita: crítica aos herdeiros do sigma. São Paulo: UNESP, 2015.

BARBOSA, Jefferson R. Skinheads chauvinistas: integralistas, os "Carecas do Subúrbio" e o nacional-socialismo brasileiro. In: PATSCHIKI, L.; SMANIOTTO, M. A.; BARBOSA, J. R. (Orgs.). Tempos conservadores: estudos críticos sobre as direitas. Goiânia: Gárgula, pp. 77-96, 2016.

COPSEY, Nigel. Contemporary British fascism: the British National Party and the Quest for Legitimacy. Nova Iorque: Palgrave Macmillan, 2004.

COSTA, Maria Regina da. Carecas do subúrbio: caminhos de um nomadismo moderno. São Paulo: Musa Editora, 2000.

GAY, Peter. O cultivo do ódio. São Paulo: Companhia das Letras, 1995.

GINZBURG, Carlo. O fio e os rastros: verdadeiro, falso, fictício. São Paulo: Companhia das Letras, 2006.

MAYNARD, Dilton Cândido Santo (Org.). Extremismos no Tempo Presente. Rio de Janeiro: Autografia, 2017.

MOURA, Luyse Moraes; MAYNARD, Dilton Cândido Santos. "Aspectos da nova extrema-direita chilena em tempos de Internet". In: MAYNARD, D.C. S. (Org.). História, neofascismos e intolerância: reflexões sobre o Tempo Presente. Rio de Janeiro: Editora Multifoco, pp. 93-116, 2012. 
MOYANO, Antonio. Neonazis: la seducción de la Svástica. Madrid: Nowtilus, 2004.

OLIVEIRA, Pedro Carvalho. O som do ódio: uma história do rock neofascista e dos neofascismos no tempo presente. Curitiba: Editora CRV, 2018.

PAXTON, Robert Owen. A anatomia do fascismo. Trad. Patrícia Zimbres e Paula Zimbres. São Paulo: Paz e Terra, 2007.

SALAS, Antonio. Diário de um skinhead: um infiltrado no movimento neonazista. São Paulo: Editora Planeta, 2006.

TEIXEIRA DA SILVA, Francisco Carlos. Neofascismo. In: TEIXEIRA DA SILVA, F. C. et al. (Orgs.). Enciclopédia das guerras e revoluções do século XX. Rio de Janeiro: Elsevier/Campus, pp. 604-606, 2004.

TEIXEIRA DA SILVA, Francisco Carlos. “Sobre os tribunais no Terceiro Reich - os fascismos e as ditaduras: o que ainda há para estudar?" In: SCHURSTER, K. et al (Orgs.). Velhas e novas direitas: a atualidade de uma polêmica. Recife: EDUPE, pp. 28-48, 2014.

Texto recebido em 08/05/2019 e aprovado em 16/07/2019 
